\title{
MOEILIJKHEDEN MET BETREKKING TOT \\ EEDSAFLEGGING EN HET DRAGEN DER WAPENEN IN BERBICE IN DE 18DE EEUW
}

DOOR

C. K. KESLER

Gewetensbezwaren van geloovigen tegen het afleggen van een, door de wereldlijke overheid gevorderden eed, tegen het dragen der wapenen en tegen het verrichten van verderen militairen dienst hebben herhaaldelijk op verschillende plaatsen tot conflicten aanleiding gegeven. Een couranten-artikel ${ }^{1}$ ) bracht verleden jaar in herinnering, hoe duizenden Doopsgezinden van oorspronkelijk Nederlandsche afkomst, wier voorvaderen tijdens de regeering van Katharina II van het gebied bij Danzig naar de Oekraine gєëmigreerd waren, in de jaren 1874-1890 naar Canada uitweken. De bloeiende koloniën, die in het laatst der $18 \mathrm{e}$ eeuw in Zuid-Rusland ontstaan waren, gingen door die emigratie te gronde en de laatste overblijfselen ervan verdwenen gedurende den vorigen oorlog van 1914-1918. Hier, gelijk dat elders voor en na het geval geweest was, werd het conflict tusschen de kolonisten en de overheid veroorzaakt door gewetensbezwaren der Doopsgezinden. Van het afleggen van den eed waren zij weliswaar vrijgesteld, maar de invoering van den algemeenen dienstplicht in Rusland in 1874 deed hen vreezen, dat voortaan met hun bezwaren tegen het voeren der wapenen, waarvan zij vroeger eveneens vrijgesteld waren, geen rekening zou gehouden worden. Daarom verlieten zij de streek, waar zij en hun voorvaderen meer dan een eeuw rustig gewoond en gewerkt hadden.

Een gelijksoortig conflict dreigde in het midden der $18 \mathrm{e}$ eeuw in Berbice de vestiging der Moravische Broedergemeente, die juist de moeilijkheden van de eerste jaren eenigszins te boven was gekomen, geheel te doen mislukken.

Reeds bij de eerste onderhandelingen over de vestiging der broe-

1) Telegraaf, 27 April 1941.

West-Indische Gids XXIV 
ders in Suriname waren deze beide punten, de verplichting tot het afleggen van een eed van trouw aan de overheid en het dienst doen in de burgerwacht, ook ter sprake gekomen. Die onderhandelingen waren gevoerd door August Gottlieb Spangenberg in opdracht van graaf Zinzendorf met het bestuur der Geoctroyeerde Societeit, Spangenberg was destijds belast met de voorbereiding van de vestiging van zendingsstations in Amerika en wel in Georgië. In November 1734 vertrok hij daarheen en hield zich toen eenigen tijd in Amsterdam op. Hier had hij besprekingen met Philip Hack ${ }^{1}$ ), een der Directeuren van de Geoctroyeerde Societeit, met den Hoogduitschen predikant H. Alstein, den Doopsgezinden predikant J. Deknatel ${ }^{2}$ ) en ten slotte met een commissie, benoemd door het bestuur der Societeit, waarvan o.a. Hack en de Secretaris Van Meel ${ }^{3}$ ) deel uitmaakten.

Reeds bij de eerste besprekingen kwam de kwestie der eedsaflegging en van den dienst in de burgerwacht op het tapijt. Spangenberg had aanvankelijk eenige vraagpunten op schrift gesteld, in het Duitsch natuurlijk, maar liet deze op raad van Hack in het Nederlandsch vertalen, daar de meesten der Directeuren van de Societeit niet voldoende met Duitsch bekend wa-

1) Philip Hack, een der directeuren van de Societeit was een Duitsch koopman, afkomstig uit Keulen, die sedert jaren in Amsterdam gevestigd was. Hij had herhaaldelijk zitting in commissies betreffende Surinaamsche zaken. Met zijn broeder Wilhelm richtte hij in 1740 de Geoctroyeerde Mineraal Maatschappij op, om onderzoek te doen naar het voorkomen van goud en andere metalen bij den Blauwen berg aan de Suriname-rivier.

2) Ds. J. Deknatel was uit Oost-Friesland afkomstig. Hij stelde veel belang in den zendingsarbeid der Broeder-gemeente, hielp de eerst uitgezonden zendelingen tijdens hun verblijf in Amsterdam voort (Sept. 1735) en nam later ook financieel aandeel in ondernemingen der gemeente in Amerika, o.a. door geld te verschaffen voor aankoop van een plantage op St. Kruis in 1738 en door in 1743 deel te nemen in de uitrusting van een schip, dat voor de gemeente naar Amerika voer.

s) Mr. Joan Hubert van Meel (1699-1769) was in 1726 Secretaris der Geoctroyeerde Societeit van Suriname, in welke functie hij zijn vader Jan Huybert van Meel was opgevolgd. Hij was een welgesteld man; zijn vermogen werd geschat op 120.800 gld. Hij bewoonde een heerenhuis op de Heerengracht bij de Reguliersgracht en bezat een buitenplaats, de hofstede Westrust onder 's-Gravenland. Deze werd na zijn overlijden gekocht door Henry Clifford, lid der voorname firma George Clifford \& Zoonen. Zijn broeder was raad-fiscaal in Suriname. Geheel tegenovergesteld aan zijn broeder, den secretaris, toonde deze zich een beslist tegenstander der Moravische broeders. Hij overleed plotseling op zijn plantage op 7 November 1740. 
ren. Deze vertaling en die van andere stukken werd verzorgd door Isaäc Lelong, een Duitscher uit Frankfort afkomstig, die reeds 40 jaren in Amsterdam gevestigd was.

Punt 6 van de vragenlijst betrof de kwestie der gewetensvrijheid. Spangenberg had daarin gevraagd: ,WWie weit sich überhaupt ihre Freyheit in Relegions- und Gewissenssachen erstrecke und was darin das Octroy mit sich bringe?" Het antwoord daarop was aanvankelijk zeer bevredigend voor den vrager en luidde: "In godsdienstzaken is het in Suriname zooals in Holland; ieder mag gelooven, wat hij wil, maar socianistische, atheistische en oproerige principen worden niet geduld". Bij de verdere onderhandelingen op 4 December in het West-Indische Huis werden toen eenige punten nader gepreciseerd en kwamen ook de kwesties van den eed en het dragen der wapenen ter sprake.

Over het eerste punt was men het vrij spoedig eens. Nadat Spangenberg verklaard had, dat de broeders niet principieel tegen het afleggen van een eed waren en dat het al of niet zweren van de formule afhing, die daarbij gebruikelijk was, verklaarden de Directeuren zich ten slotte bereid, met een z.g. Mennonisteneed genoegen te nemen.

Meer moeilijkheden gaf echter het tweede punt. Toen aan Spangenberg gevraagd werd, of de Herrnhutters zich ook wilden verdedigen, of zij dus soldaat wilden worden, antwoordde hij, dat zij in geval van oorlog bereid waren, mede te helpen door geld te geven, schansen te maken, branden te blusschen en wacht te houden. Maar, op eenigerlei wijze menschen te dooden, streed tegen hun overtuiging; daartoe waren zij niet bereid. $\mathrm{Na}$ vrij uitvoerige discussies over dit punt stemden de Directeuren er ten slotte in toe, de broeders vrij te stellen van den actieven krijgsdienst, wat trouwens practisch van weinig gewicht was, daar aanvankelijk toch niet meer dan hoogstens 7 à 8 gezinnen zouden emigreeren.

$\mathrm{Na}$ afloop der besprekingen verzocht Spangenberg het overeengekomene schriftelijk bevestigd te krijgen, wat ook geschiedde. In Augustus 1740 werd omtrent den krijgsdienst nog de volgende bepaling vastgesteld: „Bij vijandelijke of andere anvallen zullen zij (de Moravische broeders) op dezelfde wijze als de Mennonieten hier te lande behandeld worden." Behoudens eenige strubbelingen bij het begin der vestiging in Suriname heeft men zich daar aan deze bepaling gehouden en hebben geschillen over den eed en de verplichting tot het dragen der wapenen zich later niet voorgedaan. 
Anders ging het in Berbice; hier werd juist door die geschillen het zendingswerk der gemeente ernstig in gevaar gebracht en werden zelfs een paar der zendelingen genoodzaakt de kolonie te verlaten.

Met Berbice was de Broedergemeente omstreeks denzelfden tijd van de eerste vestiging in Suriname ook in betrekking gekomen en wel in het voorjaar van 1736.

$\mathrm{Na}$ den rooftocht van Cassart in 1712/'13, waarbij Berbice door diens onderbevelhebber, den baron de Mouans, voor een bedrag van $f 300.000$ gebrandschat werd, was de positie van deze kolonie geheel veranderd. De gewezen eigenaar Van Pere weigerde den, op hem getrokken, wissel van $f 181.976$ te voldoen, waarna Berbice ten slotte na lange onderhandelingen overging aan een consortium van, hoofdzakelijk Amsterdamsche, kooplieden, van welke de gebroeders Nicolaas en Hendrik van Hoorn en Pieter Schuurman de voornaamste belanghebbenden waren, de Societeit van Berbice ${ }^{1}$ ). $\mathrm{Na}$ wederom langdurige onderhandelingen met de West-Indische Compagnie en met de Staten-Generaal, waarbij Burgemeesteren van Amsterdam hun tusschenkomst verleenden, verkreeg de Societeit op 6 December 1732 een octrooi, waardoor zij, behoudens eenige bijzondere bepalingen, vrijwel onafhankelijk werd van de West-Indische Compagnie.

In Berbice bezat de Societeit in 173312 plantages en behalve deze waren er omstreeks 1740 verschillende particuliere ondernemingen aan de Berbice-rivier, de Wironje-kreek en de Canje, te zamen ten getale van 113. Drie dezer particuliere plantages, nl. Groot en Klein Poelgeest en Overmeer, gelegen aan de Berbicerivier boven de Gouvernements-plantage Savonette, behoorden aan Amsterdamsche kooplieden, de gebroeders Van Eys ${ }^{2}$ ). Met

$\left.{ }^{1}\right)$ Haar kantoor, archief en magazijn werden gevestigd in een huis op het Singel tegenover de oude Luthersche kerk.

${ }^{2}$ ) In geen der geraadpleegde werken worden deze plantage-eigenaars nader aangeduid. Het zullen zeer waarschijnlijk wel geweest zijn de Amsterdamsche kooplieden Isaäc en Jan Nicolaas van Eys, oudste en derde zoon van Gillis van Eys. Deze laatste was afkomstig uit Aken en had zich in Amsterdam gevestigd, waar hij in 1734 overleed.

$\mathrm{Zijn}$ beide bovengenoemde zoons werden voorname Amsterdamsche kooplieden; de middelste zoon Daniël vestigde zich in 1709 te Leiden. Isaäc van Eys (1682-1742) werd in de zaken van zijn vader opgenomen, die onder de firma Gillis van Eys \& Soon hoofdzakelijk in Spaansche wol handelde en gevestigd was in de Nieuwe Doelenstraat in een huis genaamd ,In 't Potasvat". Zijn inkomen werd geschat op 12 à 14.000 gld.

Jan Nicolaas van Eys (1691-1758) woonde op de Heerengracht tus- 
hen kwam Graaf Zinzendorf in aanraking tijdens zijn bezoek aan Amsterdam in het voorjaar van 1736 . $Z$ ij verzochten hem, evenals dat in Suriname geschied was, een paar zendelingen naar Berbice te doen gaan, om aan hun negerslaven het evangelie te verkondigen en hun eenig onderwijs te geven. Zinzendorf was hiertoe gaarne bereid, maar verschillende gebeurtenissen, o.a. zijn verbanning uit Saksen hielden de uitvoering ervan gedurende geruimen tijd tegen en eerst in het voorjaar van 1738 kon men ertoe overgaan, twee broeders uit te zenden.

Dit waren Johann Güttner ${ }^{1}$ ) en Ludwig Christoph Dehne ${ }^{2}$ ). Over Amsterdam, waar zij de gebroeders Van Eys en ook Lelong bezochten, reisden zij naar Berbice, waar zij op 12 September aankwamen. Twee dagen daarna bereikten zij het fort Nassau en werden op den $16 \mathrm{en}$, toen de Raad vergaderde, opgeroepen

schen de Vijzel- en N. Spiegelstraat. Hij was Directeur van den Levantschen handel; zijn inkomen werd geschat op 20 à 22.000 gld.

De firma Isaäc van Eys \& Soonen, zooals sedert 1739 de naam luidde, bestond voort tot in de $19 \mathrm{e}$ eeuw; in 1816 werd een kleinzoon van Isaäc van Eys bij K.B. van 20 Februari in den adelstand verheven met het predikaat jonkheer.

(Elias, De Vroedschap van Amsterdam).

1) Johann Güttner was afkomstig uit Friedensdorf bij Jägerndorf in Silezië. Hij was timmerman en kwam met zijn ouders naar Herrnhut. $\mathrm{Na}$ een kort verblijf in Berbice ging hij naar Suriname, waar hij te $\mathrm{Pa}$ ramaribo op 23 Augustus 1742 overleed.

2) Ludwig Christoph Dehne (ook wel gespeld Dähne) 1713-1769, was geboren te Wernigerode en kwam na eenige omzwervingen, gedurende welke hij in Jena met Spangenberg in aanraking kwam, in 1735 in Herrnhut. Hier sloot hij zich bij de gemeente aan, oefende zijn beroep van kleermaker uit en werd tevens opzichter in het weeshuis. In 1738 werd hij naar Berbice gezonden, waar hij tot 1747 bleef. Na een bezoek aan Europa ging hij in 1750 nogmaals naar Berbice, maar werd toen wegens het weigeren van den eed met hetzelfde schip, waarmede hij gekomen was, naar Europa terug gezonden. Na een verblijf te Zeist werd hij in 1751 naar Suriname gezonden, waar hij geruimen tijd op de zendingspost Ephrem aan de Corantijn doorbracht, aanvankelijk met eenige Indianen bij zich, later, toen deze weggetrokken waren, gedurende bijna twee jaren geheel alleen. Hij woonde daar in een hut in de wildernis, waar hij van tijd tot tijd bezoek van slangen, jaguars en andere dieren des wouds kreeg. Van hier werd hij wegens ziekte naar de post Saron gezonden, die op 25 Januari 1761 door Boschnegers overvallen en geheel verwoest werd. Drie jaren daarna ging hij tot herstel van zijn gezondheid naar Europa en kwam in 1765 ten derden male in Suriname, waar hij gedurende twee jaren werkzaam bleef. In Europa terug gekeerd, werd hij te Zeist zwaar ziek en overleed daar aan een hevige keel- en longontsteking op den leeftijd van 55 jaar in Februari 1769. 
om hun paspoorten en aanbevelingsbrieven over te leggen. Toen begonnen de moeilijkheden reeds, die later een scherper vorm zouden aannemen.

De Gouverneur Waterham ${ }^{1}$ ) liet hun het formulier van den eed voorlezen en wenschte, dat zij de vingers opstaken en den eed aflegden. Dit weigerden zij, verklarende, dat het tegen hun overtuiging streed, een eed te zweren, maar, dat hun ja ,,ja" en hun neen ,"neen" was. Een der leden van den Raad, de opzichtergeneraal over de Gouvernements-plantages, Johannes Andries Lössner, die tijdens een reis in Europa Zinzendorf in Parijs ontmoet had, adviseerde na eenige besprekingen, met deze verzekering genoegen te nemen, bij welk advies de Gouverneur, die niet zeer doortastend was, zich neerlegde.

De zendelingen kregen nu vergunning, naar hun bestemming door te reizen; zij meldden zich bij de plantage-directeuren, doch werden ook door dezen alles behalve met open armen ontvangen, in weerwil van de aanbevelingsbrieven, die zij van de eigenaars hadden medegebracht.

Voorloopig was dus het gevaar voor hen en voor eenigen, die na hen kwamen, afgewend, bij weigering van den eed onmiddellijk terug gezonden te worden, iets, waartoe de Raad aanvankelijk geneigd scheen te zijn. Nadat zij versterking uit Europa gekregen hadden door aankomst van eenige broeders, besloten zij in 1740 hun werk op de plantages, dat tot dusver weinig vruchten gedragen had, op te geven en een eigen nederzetting te stichten, waar zij beter met de Indianen in aanraking konden komen. Deze zendingspost werd gevestigd aan de Wironje-kreek, een linkerzijrivier van de Berbice-rivier, die eenige mijlen beneden de plantages Groot- en Klein Poelgeest in de hoofdrivier uitloopt. Deze nederzetting kreeg den naam Pilgerhut.

Hier konden de broeders eenige jaren vrij rustig hun werk verrichten in weerwil van tegenwerking van verschillende zijden, welke tegenwerking echter niet zoo bijzonder voelbaar was, zoolang Lössner Gouverneur van Berbice was.

De Gouverneur Waterham nl. had zich door gebrek aan tact en energie vrijwel onmogelijk gemaakt, waartoe minder gepaste gedragingen van zijn schoone vrouw het hare hadden bijgedragen,

1) $\mathrm{Bij}$ de reorganisatie van het bestuur van Berbice werd besloten, den toenmaligen Commandeur Anthony Thierens wegens zijn vele „,misuses en exactiën" te ontslaan. In zijn plaats werd 24 Maart 1733 tot Gouverneur benoemd Bernhard Waterham, vaandrig in het regiment van den Graaf van Lippe. 
waarom hij op 6 April 1740 door Directeuren werd ontslagen. In zijn plaats werd Lössner benoemd, die gedurende 9 jaren het bewind voerde, doch ook al weinig voldoening aan de Directie gaf. $\mathrm{Na}$ herhaalde oneenigheden met den toenmaligen opzichtergeneraal over de Gouvernements-plantages, Hendrik Blankenberg, werd Lössner, nadat Blankenberg zijn zaak in Holland bepleit had, in het ongelijk gesteld en op 2 Mei 1749 ontslagen.

Zijn opvolger was Jan Frederik Colier, geboren te Neuchatel, die gedurende vijf jaren in Suriname gediend had en daarna een betrekking gehad had bij het „Comptoir des vivres" van het Engelsche leger. Colier werd op 9 Mei 1749 te Amsterdam benoemd en kwam 28 September d.a.v. in Berbice aan met verschillende scherpe opdrachten der Directeuren, o.a. om van Lössner strikte rekening en verantwoording te eischen en hem daarna naar Holland op te zenden. Om te voorkomen, dat hij de vlucht nam, was hij gemachtigd, hem desnoods in arrest te stellen ${ }^{1}$ ). Verder bleek al spoedig, dat hij bepaalde opdrachten had ontvangen, om de zaak der eedsaflegging en het dienen in de burgerwacht, wat den Moravischen broeders betrof, definitief te regelen.

Dit straffere optreden tegen de Herrnhutters zal wel beïnvloed geworden zijn door een waarschuwing tegen hen van de zijde van Amsterdamsche predikanten, die in 1739 onder den titel „,Herderlijke en Vaderlijke Brief van den Kerke-Raad te Amsterdam" verschenen was. Daarbij kwam, dat ook uit Berbice aanklachten tegen de Herrnhutters bij de Directie waren ingekomen, o.a. van de zijde van den predikant Johannes Christiaan Frauendorff. Deze was afkomstig uit Saksen, was gedurende eenige jaren predikant te Namen geweest en in 1735 in Berbice aangesteld. Hij was allerminst iemand, die geschikt was, om de zoo noodige eensgezindheid onder de blanke bevolking te bevorderen. Netscher vermeldt van hem, dat hij intolerant, inhalig en twistziek van aard was, dat hij al spoedig in onmin leefde met nagenoeg alle kolonisten en dat tallooze brieven van hem aan de Directie en copieën van missives van Directeuren aan hem op het Rijksarchief berusten. Hij wordt in die brieven herhaaldelijk berispt wegens zijn onverdraagzaamheid en weinig Christelijke opvattingen.

Vóór hij naar Berbice kwam, was er gedurende vele jaren geen predikant in de kolonie geweest en had de Protestantsche kerk, die omstreeks 1730 aan de Berbice-rivier tegenover de uitmonding

1) Daartoe schijnt het echter niet gekomen te zijn; Lössner gaf regelmatig het bewind over en vertrok op 29 Mei 1750 uit Berbice. 
van de Wironje-kreek gebouwd was, ongebruikt gestaan. Ds. Frauenhoff nam aanvankelijk met zijn gezin zijn intrek in het fort Nassau, waar op de eerste verdieping boven de pakhuizen der Compagnie en de kazerne, de woningen van den Gouverneur, den Secretaris en de officieren, benevens een vergaderzaal voor de Raden van Politie en een vrij ruim kerklokaal zich bevonden. Al spoedig maakte de predikant het allen door zijn veeleischendheid zoo lastig, dat de Gouverneur zich haastte, bij de kerk aan de Wironje-kreek een woning voor hem te laten bouwen, waardoor hij gelegenheid kreeg, hem uit het fort te verwijderen.

De bezwaren van den predikant waren hoofdzakelijk gericht tegen de prediking der zendelingen, die volgens hem van de geloofsbelijdenis der Gereformeerde kerk in verschillende opzichten afweek. De klachten van het Bestuur en van vele planters tegen hen waren van anderen aard. Het Bestuur had bezwaar tegen hun bemoeiingen met de Indianen, die door den invloed der zendelingen zouden worden afgehouden van hun gewone bezigheden, de jacht en vooral de visscherij ten dienste der Compagnie. Niet alleen het bestuur van Berbice maakte hun daar een verwijt van; ook uit de naburige kolonie Essequebo, die aan de West-Indische Compagnie toebehoorde, werden soortgelijke klachten vernomen. De rondzwervende Indianen uit Demerary, dat sedert 1746 als onderhoorigheid van Essequebo geëxploiteerd werd, schijnen in vrij grooten getale, waarschijnlijk aangetrokken door het voor hen vreemde van onbaatzuchtige, welwillende blanken, die daar woonden, naar Pilgerhut getrokken te zijn en daar in den omtrek tijdelijk verblijf te hebben gehouden. Dit was allerminst naar den zin van den wd. Commandeur van Essequebo, Adriaan Spoors ${ }^{1}$ ). In het begin van het jaar 1751 beklaagde deze zich schriftelijk bij den gouverneur van Berbice over dit wegtrekken der Indianen uit Demerary en dreigde, dat, als hij de zendelingen, aan wier invloed hij dit toeschreef, in zijn macht mocht krijgen, hij hen zonder vorm van proces onmiddellijk zou laten ophangen. De zendelingen achtten het dan ook ongeraden in te gaan op een aanbod, dat hun van particuliere zijde juist in dien tijd gedaan werd, nl., een plantage van 2000 akkers aan de Demerary-rivier aan hen te verkoopen. Zij begrepen volkomen, dat voor deze transactie zeer zeker niet de goedkeuring van het bestuur van Essequebo te verkrijgen zou zijn.

En, wat van meer belang was, de Directeuren in Amsterdam

1) Hij was Secretaris en nam tijdens het verlof van den Commandeur L. Storm van 's-Gravensande diens functiên waar. 
waren ook al allerminst tevreden over den gang van zaken in hun kolonie, waar nog niet veel verbetering te zien was, in weerwil van de scherpe opdrachten, die zij den nieuwen gouverneur hadden medegegeven. Er werden wel vele brieven geschreven, maar twisten en oneenigheden bleven in Berbice aan de orde van den dag en niet zelden leidden deze tot handtastelijkheden, die dan weer allerlei processen ten gevolge hadden. Wel hadden de Directeuren ten laatste de gouverveurs aangemaand, het hunne te doen, om het aantal daarvan wat te verminderen, o.a. door persoonlijk tusschen beide te komen, maar veel gaven deze vermaningen niet. Netscher oordeelt dan ook: „Wij gelooven niet, dat eene kolonie op minder oordeelkundige wijze is bestuurd geworden, dan Berbice van 1720 tot 1760, zoowel van uit het Vaderland als in de kolonie zelve".

$\mathrm{Om}$ nu althans te trachten, hierin eenige verbetering te brengen, besloten Directeuren in 1750 een hunner als gemachtigde naar de kolonie te zenden, hopende, dat door zijn optreden verschillende geschillen beslecht en niet afgedane zaken tot een goed einde gebracht zouden worden.

Deze commissaris, Boulée, kwam in September in Berbice aan. Eenige der onderdeelen van zijn opdracht waren de regeling van de kwestie der eedsaflegging en van het dienst doen in de burgerwacht door de Moravische broeders en verder het onderzoeken van de klachten, die tegen hen van verschillende zijden waren ingebracht.

Deze missie had echter al even weinig uitwerking, als de vele brieven en aanschrijvingen, die uit Amsterdam naar Berbice gingen. Boulée kon trouwens slechts zeer weinig of niets in de kolonie uitrichten, daar hij spoedig na zijn aankomst aldaar en wel op 19 November plotseling overleed. Het weinige, dat hij tijdens zijn kortstondig verblijf daar had kunnen doen, was met den gouverneur te zamen een voorloopig onderzoek instellen, om gewenschte gegevens te verzamelen. Wat den Herrnhutters betreft, had er een onderhoud plaats met twee hunner, Schumann ${ }^{1}$ ), een zeer energiek en bekwaam man, die voortaan in hoofdzaak de onderhandelingen met het bestuur voerde, en Klarup. Dit onderhoud

2) Zie W. I. G. XXII No. 9 blz. 269.

Het is eigenaardig op te merken, hoe op Schumann, die toch een talenkenner was, zijn Hollandsche omgeving inwerkte. In zijn brieven en dagboeken, die in het Duitsch gesteld zijn, gebruikt hij behalve nu en dan Latijnsche en Grieksche woorden en uitdrukkingen, ook herhaaldelijk Hollandsche woorden, waar men Duitsche zou verwachten. 
was door de zendelingen zelf uitgelokt, die vernomen hadden, dat van verschillende zijden klachten tegen hen waren ingebracht en dat er overwogen werd, hen uit de kolonie te verwijderen en het daarom beter achtten, geen oproeping ter verantwoording af te wachten, maar zoo spoedig mogelijk voor de verdediging hunner belangen zelf te zorgen.

Dit onderhoud had op 12 November op het fort plaats. Aanvankelijk wilde de gouverneur de beide broeders niet ontvangen, maar, toen Schumann aanhield, werden zij toch ten laatste toegelaten. Boulée woonde het grootste gedeelte van het gesprek bij.

De broeders vernamen toen, dat de klachten drieërlei waren en wel:

1. de vrees, dat de Indianen door de prediking opstandig zouden worden;

2. de weigering wapenen te dragen en

3. het bezwaar tegen de eedsaflegging, waardoor tevens onmogelijk werd, zendelingen in eenig ambt te benoemen ${ }^{1}$ ).

Het resultaat van dit onderhoud was, dat den zendelingen 6 à 8 maanden tijd gelaten werd om hun verdere houding te bepalen. Inmiddels konden zij zich schriftelijk tot de Directie te Amsterdam wenden. De gouverneur gaf zelfs in overweging, dat een paar der zendelingen naar Amsterdam zouden gaan, om de zaken met de Directie persoonlijk te bespreken. Toen Schumann hierop antwoordde, dat op dit oogenblik bezwaarlijk broeders gemist konden worden, maar, dat hij binnen kort nieuw uitgezondenen verwachtte, riep Colier uit: ,,Ja, daarop zal ik wel passen, dat er geen meer hier komen!"

De nieuw aangekomenen, die 10 Maart 1750 in Berbice arriveerden, waren Dehne en het echtpaar Beutel. Aanvankelijk wilde de gouverneur hun niet veroorloven naar Pilgerhut, door te reizen, maar na eenig over en weer praten verkregen zij toch vergunning daartoe en kwamen twee dagen later op de zendingspost aan.

Het bleek nu weldra, dat de gouverneur niet van zins was, de zaken nog langer slepende te laten. Beide punten van geschil, de

1) Er bestonden destijds in Berbice verschillende strenge bepalingen en op overtreding ervan waren zware straffen gesteld. Zoo was ieder verplicht, een onbezoldigd ambt, waarin hij van bestuurswege benoemd werd, te aanvaarden, op straffe bij weigering uit de kolonie verwijderd te worden.

Mankeeren bij de oefeningen van de burgerwacht werd twee keer met geldboete bestraft en den derden keer eveneens met uitwijzing. 
eedsaflegging en het dienen in de burgerwacht, pakte hij ongeveer tegelijkertijd aan, terwijl hij ook een poging deed, om de verhouding van de Indianen tot het bestuur en de zending eenigszins geregeld te krijgen.

Beutel en Dehne werden opgeroepen op 6 April op het fort te verschijnen om den eed van trouw af te leggen. Tevens ontvingen de broeders het bevel maandelijks vier hunner Indianen naar het fort te zenden om daar voor het bestuur te werken.

In de raadsvergadering weigerden de twee opgeroepenen, evenals Dehne dat reeds in 1738 tegenover den gouverneur Waterham gedaan had, den eed af te leggen, waarop beiden op 17 April schriftelijk aanzegging kregen, per eerstkomende gelegenheid de kolonie te verlaten.

Wat het exerceeren betreft, was reeds in een raadsvergadering op 11 Augustus 1750 uitgemaakt, dat ook de zendelingen daartoe verplicht waren, maar het duurde nog tot Januari van het volgende jaar, eer er een poging gedaan werd dat besluit ten uitvoer te brengen. Dat werd niet zoozeer veroorzaakt door lankmoedigheid van het bestuur, als wel door het vrijwel volkomen ontbreken van discipline in Berbice. Dit gemis bleek wel sterk toen het raadsbesluit den broeders officieel bekend gemaakt zou worden. Hiermede werd een commissie, bestaande uit den gouvernementssecretaris en twee luitenants van het garnizoen belast. De secretaris vertrok het eerst, maar kort nadat deze zich op reis begeven had, kreeg een der luitenants een hevigen twist met den gouverneur, zoodat deze het toen beter achtte, voorloopig maar van het uitzenden der commissie af te zien. De secretaris werd door middel van een hem achterna gezonden bode ijlings terug geroepen en zoo bleef ook deze zaak weder hangende.

Ook de uitwijzing van Dehne en Beutel kon vooreerst niet ten uitvoer gelegd worden. Wel was hun aangezegd per eerste gelegenheid de kolonie te verlaten, maar het duurde nog geruimen tijd, eer die eerste gelegenheid zich voordeed. De verbinding toch van het moederland met Amerika was in het midden der 18 e eeuw op verre na niet zoo regelmatig, als zij in de rustige jaren van de $19 \mathrm{e}$ en van deze eeuw zou worden. Van onmiddellijk weer vertrekken was dus geen sprake en tijdens het wachten op reisgelegenheid werd de echtgenoote van Beutel zoo ziek, dat zij bezwaarlijk de zeereis op nieuw zou kunnen aanvaarden. Dit werd in een attest door den chirurgijn van het fort, die haar eenige malen bezocht, vastgesteld. Het was inmiddels Juli geworden en op den 2en dezer maand begaf Beutel zich naar het 
fort, om den gouverneur te verzoeken, hem en zijn vrouw uitstel van hun vertrek te verleenen, tot de laatste voldoende hersteld zou zijn. Tevens bezorgde hij een rekest aan den Raad van Politie, waarin de verschillende punten van geschil nogmaals behandeld werden. In een bijlage bij dit rekest werd het mondeling door Beutel gedane verzoek om uitstel herhaald en Dehne sloot zich hierbij aan. Tevens werd het attest van den chirurgijn overgelegd.

In de eerstvolgende vergadering van den raad werd dit rekest met bijlagen behandeld. Op het verzoek om uitstel van het echtpaar Beutel werd gunstig beschikt; de uitwijzing van Dehne werd gehandhaafd en deze zag zich dus genoodzaakt, daar inmiddels een schip zou vertrekken, op 31 Augustus de reis te aanvaarden. Wat verder den overigen zendelingen betreft, omtrent hen zou beslist worden, zoodra de gouverneur en de raad de noodige nadere instructies van de Directeuren uit Amsterdam zouden ontvangen hebben.

Deze instructies lieten echter weder geruimen tijd op zich wachten en inmiddels wijzigde zich de gezindheid van den gouverneur, die tot dusver beslist vijandig geweest was, belangrijk ten gunste der zendelingen. Dit werd veroorzaakt door een bezoek, dat hij met den secretaris op 14 September aan Pilgerhut bracht. Een nauwkeurige inspectie overtuigde hem ervan, dat hij in verschillende opzichten onjuiste rapporten had ontvangen. O.a. was gerapporteerd, dat de Indianen, die bij de nederzetting woonden, opdracht gekregen hadden, zich bij nadering van blanken in het bosch te verschuilen, zoodat hun aantal niet juist zou kunnen worden vastgesteld. Het bleek, dat dit volkomen onwaar was; de Indianen, die aanwezig waren, bleven rustig aan hun werkzaamheden. Van de aanplantingen en de behuizing van blanken en Indianen kreeg de gouverneur verder een gunstigen indruk, zoodat hij bij het afscheid betuigde, dat zijn meening omtrent den arbeid der zendelingen belangrijk gewijzigd was. De kwestie was daarmede echter nog niet van de baan.

Op 6 October werd een buitengewone vergadering van den raad gehouden, waarin kennis genomen werd van de instructies van de Directie, die inmiddels eindelijk uit Amsterdam ontvangen waren. Deze bevalen, onveranderlijk vast te houden aan den eisch van het afleggen van den eed van trouw en van het dienen in de burgerwacht, terwijl verder voor iederen gedoopten Indiaan hoofdgeld betaald moest worden. De gunstige gezindheid van den gouverneur, die door eenige leden van den raad gedeeld werd, maakte, dat den broeders ten slotte nogmaals drie maanden uit- 
stel gegeven werd en wel tot de volgende raadsvergadering, welke op 4 Januari 1751 zou plaats hebben.

Inmiddels werd ook in het moederland gewerkt om een gunstiger stemming bij de Directie ten opzichte der zending te verkrijgen. Hiermede belastte zich een der voornaamste leden der gemeente in Holland, nl. Abraham von Gersdorf. Zijn relaties in de hoogste kringen der republiek zouden hem waarschijnlijk wel in staat stellen, invloed ten goede te oefenen. In Mei 1751 schreef hij een in het Fransch gestelden brief met uitvoerige toelichting over de zaken in Berbice aan den Erfstadhouder. Aan het stadhouderlijke hof was men persoonlijk met Zinzendorf bekend, o.a. door een bezoek, dat hij, nog als student, daar te Leeuwarden in 1719 en later nogmaals, toen vergezeld door zijn gemalin en zijn dochter in 1736 gebracht had.

Ongetwijfeld zullen de bemoeiïngen van Von Gersdorf en van anderen niet zonder invloed op de houding der Directie ten opzichte der zending gebleven zijn, vooral daar de Erfstadhouder sedert zijn benoeming tot Directeur-Generaal der beide Compagnieën in 1747 belangrijken invloed op koloniale zaken verkregen had.

Maar de doorslag werd toch gegeven in Berbice zelf door een veranderde houding der gemeente, nadat de zendeling Wilhelm Zander ${ }^{2}$ ) daar was aangekomen.

Hij was uit Europa uitgezonden om verschillende zendings-

1) Abraham von Gersdorf (1704-1784) was o.a. „Geheimer Kriegsrat" in Dresden. In 1740 trad hij tot de Broedergemeente toe en bekleedde in haar dienst verschillende functies in Holland, Pruisen, Engeland en elders.

2) Wilhelm Zander (1716-1781) was geboren te Quedlinburg. Hij kwam in 1734 te Jena met Zinzendorf in aanraking en trad in 1738 tot de gemeente toe. Gedurende eenigen tijd werden hem werkzaamheden in Stralsund toevertrouwd en in 1741 werd hij naar Amerika gezonden. Van hier terug gekeerd werd hem twee jaar later de visitatie der zendingsposten in Suriname opgedragen. Vóór zijn vertrek daarheen huwde hij op 4 Juni met Johanna Magaretha Müller. Op 23 October kwam het echtpaar te Paramaribo aan, begaf zich na een verblijf in Suriname naar Berbice en in 1749 naar Bethlehem in Amerika. Op die reis overleed zijn echtgenoote op zee op de hoogte van St. Thomas. $\mathrm{Na}$ in Europa teruggekeerd te zijn, werd hij in 1751 opnieuw naar Berbice gezonden met opdracht, den eed af te leggen (zijn bereidheid daartoe stond op zijn pas vermeld) en de overige zendelingen te bewegen, hetzelfde te doen. In 1756 ging hij voor de tweede maal naar Suriname en huwde daar met de weduwe Gräbenstein. Bij den aanval der Boschnegers op de zendingspost Saron in 1761 werd hij gewond en keerde toen naar Zeist terug. Zijn laatste levensjaran bracht hij als predikant te Blokzijl in Overijsel door, waar hij in 1781 overleed. 
posten in Amerika te visiteeren en had voor zijn vertrek een onderhoud met Zinzendorf gehad over de kwestie der eedsaflegging. Deze had als zijn meening te kennen gegeven, dat daartegen geen bezwaar bestond. In Mei 1739 had hij reeds verklaard: „Es ist ganz kein Lehrsatz bei uns, dass men nicht schwören dürfe. Es wird davon niemals geredet...." Of een lid der gemeente al of niet een eed wilde afleggen, moest hij met zijn eigen overtuiging uitmaken. En eischte de overheid een eed van trouw en werd door weigering daarvan de zaak der zending in gevaar gebracht, dan was het beter zich niet te verzetten, maar zich te onderwerpen, of het land te verlaten, indien men die onderwerping niet met zijn geweten overeen kon brengen.

Wat nu Berbice betreft, kreeg Zander de opdracht, den eed af te leggen - op zijn pas werd vermeld, dat hij daartoe bereid was - en de overige zendelingen op te wekken, zijn voorbeeld te volgen. Aldus handelde hij dan ook: op 4 Januari legde Zander den eed af en zijn voorbeeld werd door anderen gevolgd. Twee gehuwde en een ongehuwde zendeling bleven bij hun bezwaren volharden en verlieten Berbice. Een gezin ging naar Pennsylvanië, de anderen gingen naar Europa. Het laatst onderwierp Schumann zich. Hij werd op 4 April beëedigd, nadat hij nog te voren op 28 Maart in een onderhoud met den gouverneur Colier verklaard had, dat hij bereid was, zich te onderwerpen, doch alleen, daar hij vreesde door voortgezette weigering de geheele zaak der zending in Berbice in gevaar te zullen brengen.

Met de onderwerping der gemeente in zake de eedsaflegging namen het Bestuur in Berbice en de Directie te Amsterdam genoegen; omtrent het dienen in de burgerwacht, het betalen van hoofdgeld voor gedoopte Indianen en andere geschilpunten werden de zendelingen verder niet lastig gevallen. Trouwens een en andermaal had de gouverneur reeds verklaard, dat dit ondergeschikte zaken waren; het kardinale punt, waarom het bij de Directie ging, was de zaak van het afleggen van den eed. Toen deze naar haar genoegen geregeld was, konden de Moravische broeders nog gedurende eenige jaren vrij rustig hun werk voortzetten. Niet lang echter; in Februari 1763 brak de groote slavenopstand uit, die Berbice aan den rand van den afgrond bracht. In Maart ging de nederzetting Pilgerhut in vlammen op en namen de zendelingen, die er toen waren, de vlucht naar Demerary. Daardoor kwam een einde aan den zendingsarbeid in Berbice. Schumann beleefde deze catastrophe niet; hij was op 10 October 1760 te Pilgerhut overleden. 